\title{
Influência de fatores genéticos e ambientais sobre as características produtivas no rebanho eqüino do Exército Brasileiro
}

\author{
Vinício Aurélio Lagoas Campos ${ }^{1,2}$, Concepta McManus ${ }^{3}$, Beatriz Helena Fuck ${ }^{1,2}$, Lizângela \\ Cassiano1, Bruno Freitas Pinto ${ }^{1,2}$, Auro Braga ${ }^{1,2}$, Helder Louvandini ${ }^{3}$, Laila Talarico Dias ${ }^{3}$, \\ Rodrigo de Almeida Teixeira ${ }^{3}$
}

\footnotetext{
${ }^{1}$ Mestrando do curso em Ciências Agrárias da Faculdade de Agronomia e Medicina Veterinária, Universidade de Brasília, Cx. Postal 04508 , Brasília-DF, CEP: 70910-900.

2 Ministério da Defesa, Quartel Geral, Setor Militar Urbano, Brasília DF.

${ }^{3}$ Faculdade de Agronomia e Medicina Veterinária, Universidade de Brasília, Cx. Postal 04508, Brasília-DF, CEP: 70910-900.
}

RESUMO - Objetivou-se estimar parâmetros genéticos e fenotípicos para peso e altura (4.860 registros) em cavalos de quatro grupos genéticos - Brasileiro de Hipismo (BH), Puro-Sangue Inglês (PSI), Hanoveriano (HAN) e Sem Raça Definida (SRD) - por meio de informações de 1629 animais do Exército Brasileiro coletadas entre 1977 e 2002. Foram considerados fixos os efeitos de ano e mês de nascimento, idade da mãe, sexo do potro, ano e mês de mensuração e grupo genético. O mês de nascimento não afetou a altura ou o peso na população, exceto nos animais mais velhos. O sexo influenciou a altura, mas não afetou o peso dos animais de 21 meses e dos adultos e a raça influenciou a altura somente nos animais de 18 a 21 meses de idade e nos adultos. A influência dos efeitos fixos foi menor nos animais BH que nos SRD. As herdabilidades para o peso dos animais BH foram altas nas diversas idades, mas foram baixas para a altura. O comportamento do peso e da altura foi semelhante para as raças BH e SRD. De modo geral, nos dois grupos genéticos (BH e SRD), a herdabilidade do peso aumentou conforme as faixas etárias.

Palavras-chave: altura, correlações genéticas, herdabilidade, peso

\section{Genetic and environmental effects on production traits of an equine herd of the Brazilian army}

\begin{abstract}
This study aimed to estimate genetic and phenotypic parameters for weight and height (4860 records) of equines from four genetic groups: Brazilian Showjumper (BH), Thoroughbred (PSI), Hanoverian (HAN) and No Defined Breed (SRD). Data collected from 1977 to 2002 on 1629 animals was provided by the Brazilian Army. Models used for analyses included the fixed effects of month and year of foaling and measuring, age of dam, foal sex and genetic group. Foaling month did not affect height or weight of the horses, except for older animals. The sex effect influenced height but not weight of 21-month-old animals and adults. The genetic group influenced height between 18 and 21 months of age, as well as height of adults. BH was less influenced by environmental effects than SRD. Heritabilities for weights of BS were high at various ages, but were low for height. Overall, heritability estimates for weight of BH and SRD increased as age increased.
\end{abstract}

Key Words: genetic correlation, heritability, weight, height

\section{Introdução}

O Exército Brasileiro utiliza eqüinos para atividades de patrulhamento e guarda de áreas de fronteira e campos de instrução espalhados pelo território nacional para cerimonial militar e práticas desportivas como salto, concurso completo de equitação, pólo e adestramento. Assim, não é fácil produzir animais com versatilidade e adaptabilidade a esta gama de atividades, considerando tamanha diversidade de ambientes espalhados pelos rincões do Brasil. Além disso, como muitas destas atividades estão exclusivamente relacionadas às Forças Armadas, torna-se mais difícil encontrar animais adequados em outras instituições.

Atualmente, as raças mais utilizadas para montaria no exército nacional são: Brasileiro de Hipismo(BH), Hanoveriano (HAN), Puro-Sangue Inglês (PSI) e Sem Raça Definida (SRD). Ressalta-se que os animais SRD devem atingir um padrão préestabelecido para o cavalo do tipo militar, como altura mínima de 1,45 m, bons aprumos, boa capacidade cardio-respiratória, boa cobertura muscular, medidas lineares harmoniosas, além de ter como andadura o trote, não sendo permitidos cavalos marchadores (SgEX, 2003). 
Para o suprimento de animais para desempenhar o papel atribuído ao cavalo militar no Brasil, é fundamental adotar sistemas de produção visando à obtenção de animais adequados para o serviço com mínimo de perdas em termos de reprodução, defeitos genéticos ou congênitos. Deve-se, portanto, investir no controle rigoroso da eficiência reprodutiva e do potencial genético dos reprodutores e das matrizes para proporcionar ambiente adequado à manifestação deste potencial. O objetivo neste trabalho foi avaliar as influências genéticas e ambientais na altura e no peso dos cavalos criados pelo Exército Brasileiro.

\section{Material e Métodos}

Foram utilizados dados coletados das Organizações Militares distribuídas em todo o território nacional, exceto da Amazônia. Aos dois anos de idade, os animais foram destinados aos quartéis, onde foram submetidos a doma racional no $1^{\mathrm{o}}$ e $2^{2} \mathrm{o}$ anos de vida e, posteriormente, a treinamento leve, quando os machos foram castrados. Nos quartéis de destino, receberam alimentação composta de volumoso e concentrado com $14 \%$ de PB, dividida em três fases. O regime de criação dependeu da disponibilidade de área, ficando entre a estabulação e a semi-estabulação. $\mathrm{O}$ acesso ao volumoso, portanto, foi muitas vezes restrito pelas limitações físicas do estabelecimento. Os eqüinos foram transferidos entre os quartéis conforme a necessidade, ou por estarem vinculados a determinado militar que os utilizava em competições hípicas.

Os animais receberam tratamento contra endoparasitos três vezes ao ano e a profilaxia incluía vacinação contra influenza eqüina, tétano, encefalomielite, raiva e adenite equiina, além de exames semestrais para diagnóstico de anemia infecciosa eqüina (AIE).

Foram analisados 4.860 registros de desempenho de animais Hanoverianos, Brasileiro de Hipismo, Puro-Sangue Inglês e SRD. A altura da cernelha e o peso do animal foram medidos várias vezes ao longo da vida do animal, dos seis meses à idade adulta. As análises de variância foram realizadas por meio do programa estatístico Statistical Analysis System (SAS, 1996), pelo procedimento General Linear Model (PROC GLM) e Correlações (PROC CORR).

$\mathrm{O}$ modelo utilizado na avaliação dos efeitos citados sobre as medidas lineares foi o seguinte:

$\mathrm{Y}_{\mathrm{ijklmno}}=\mu+\mathrm{O}_{\mathrm{i}}+\mathrm{R}_{\mathrm{j}}+\mathrm{M}_{\mathrm{k}}+\mathrm{A}_{1}+\mathrm{MM}_{\mathrm{m}}+\mathrm{AM}_{\mathrm{n}}+\mathrm{e}_{\mathrm{ijklmno}}$ em que $\mathrm{Y}_{\mathrm{ijklmno}}=$ variável dependente; uma das duas medidas de desenvolvimento; $\mu=$ média geral, associada à variável dependente; $\mathrm{O}_{\mathrm{i}}=$ efeito fixo do iésimo sexo do animal ( $\mathrm{i}=$ macho ou fêmea); $\mathrm{R}_{\mathrm{j}}=$ efeito fixo do jésimo raça
( $\mathrm{j}=$ Hanoveriano, Brasileiro de Hipismo, PSI ou SRD); $\mathrm{M}_{\mathrm{k}}=$ efeito fixo do $\mathrm{k}^{\text {ésimo }}$ mês de nascimento (J,..,D); $\mathrm{A}_{1}=$ efeito fixo do $\mathrm{l}^{\text {ésimo }}$ ano de nascimento; $\mathrm{MM}_{\mathrm{m}}=$ efeito fixo do $k^{\text {ésimo }}$ mês de medição $(\mathrm{J}, \ldots, \mathrm{D}) ; \mathrm{AM}_{\mathrm{n}}=$ efeito fixo

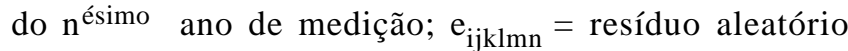
associado a cada observação.

Para as estimativas dos componentes de (co)variância e obtenção da herdabilidade e repetibilidade, adotou-se o método de máxima verossimilhança restrita livre de derivadas por meio do pacote MTDFREML (Boldman et al., 1995) ajustando-se a equação:

$$
\mathrm{Y}=\mathrm{X} \beta+\mathrm{Z}_{1} \mathrm{a}+\mathrm{Z}_{2} \mathrm{~m}+\mathrm{Z}_{3} \mathrm{pe}+\mathrm{e}
$$

em que: $\mathrm{Y}=$ vetor $(\mathrm{Nx} 1)$ de observação do animal; $\beta=$ vetor de efeitos fixos (sexo, mês e ano de nascimento, mês e ano de mensuração, raça, ordem de parição) no modelo; $a=$ vetor dos efeitos genéticos diretos; $m=$ vetor dos efeitos genéticos maternos; $p e=$ vetor dos efeitos de ambiente permanente materno; $\mathrm{X}, \mathrm{Z}_{1}, \mathrm{Z}_{2}, \mathrm{Z}_{3}=$ matrizes incidência associadas a cada efeito aleatório, respectivamente; $e=$ vetor dos erros aleatórios associados a cada mensuração;

Os efeitos genético materno e de ambiente permanente materno foram incluídos quando necessários.

A análise de variância para as medidas de altura e peso foi realizada utilizando-se todos os registros disponíveis para todos os grupos genéticos. Os animais foram divididos em dez grupos da seguinte forma: grupo $1=6$ meses de idade; grupo $2=9$ meses; grupo $3=1$ ano; grupo $4=15$ meses; grupo $5=18$ meses; grupo $6=21$ meses; grupo $7=$ 24 meses; grupo $8=36$ meses; grupo $9=48$ meses; e grupo $10=$ animais acima de 48 meses de idade.

As estimativas de herdabilidade das medidas de peso e altura e as correlações entre essas características foram obtidas utilizando-se somente os registros das raças Brasileiro de Hipismo e Sem Raça Definida, em virtude do maior número de animais no conjunto de dados (Tabela 1).

Tabela 1 - Número de animais utilizados para cada raça estudada Table 1 - Number of animals by breed

\begin{tabular}{lc}
\hline $\begin{array}{l}\text { Raça } \\
\text { Breed }\end{array}$ & $\begin{array}{c}\text { Número de animais } \\
\text { Number of animals }\end{array}$ \\
\hline $\begin{array}{l}\text { Puro-Sangue Inglês (PSI) } \\
\text { Thoroughbred (Th) }\end{array}$ & 135 \\
Brasileiro de Hipismo (BH) \\
Brazilian Show jumper (BS) \\
$\begin{array}{l}\text { Hanoveriano (HAN) } \\
\text { Hanoverian (HAN) }\end{array}$ \\
$\begin{array}{l}\text { Sem Raça Definida (SRD) } \\
\text { No Defined Breed (NDB) }\end{array}$ \\
\hline
\end{tabular}


Para estas análises, os animais foram divididos em quatro grupos: grupo $1=$ um ano de idade; grupo $2=$ dois anos; grupo $3=$ três anos; grupo $4=$ mais de quatro anos de idade .

\section{Resultados e Discussão}

Como esperado, a altura e o peso dos animais aumentaram de acordo com a classe de idade (em meses) (Figura 1). Entretanto, no grupo 8, os animais nascidos em julho e agosto foram os mais altos, enquanto os nascidos em janeiro e fevereiro apresentaram as menores médias de altura aos 36 meses (o mesmo ocorreu para a característica peso). Os animais do grupo 10 nascidos no inverno e na primavera foram maiores e mais pesados que aqueles nascidos no verão. Estes resultados corroboram os encontrados por Heusner (1992) e Thompson et al. (1994), mas divergem dos descritos por Pagan et al. (1996). Os animais que nascem no inverno e no início da primavera eram filhos de éguas que entraram em atividade reprodutiva e conceberam no início da estação reprodutiva e, portanto, estavam em boas condições nutricionais e sanitárias, o que, provavelmente, proporcionou melhores condições para a gestação.

Quanto à análise de variância, o efeito de mês de nascimento não afetou a altura ou o peso dos animais na maioria dos grupos, exceto para os grupos 8 ( 36 meses) e 10 (mais de 48 meses) (Tabela 2). Conforme descrito anteriormente, os animais do grupo 8 nasceram entre os meses de julho e agosto e os do grupo 10, no inverno e na primavera. Assim, o bom estado nutricional pode ter sido resultado do uso de pastagens de inverno com forrageiras de elevado valor nutritivo, como aveia, azevém e trevo, associado ao uso de concentrado, como indicado na literatura. O inverno é considerado época em que a vegetação de campo natural é composta predominantemente de gramíneas, comum na região, e possui menor qualidade e quantidade de proteína e, principalmente, de energia (Alfaya et al., 2001a). A suplementação com alimentos energéticos-protéicos é imprescindível para a complementação da dieta de animais em crescimento pastejando em áreas de campo natural no inverno (Alfaya et al., 2001b). Entretanto, o uso de suplementação energética em pastagem cultivada de inverno possibilita o aumento significativo da produção animal em relação à utilização exclusiva da pastagem, resultando em aumento no ganho de peso individual, à carga animal e ao ganho de peso vivo por hectare com animais jovens (Rocha et al., 2001).

$\mathrm{O}$ ano de nascimento foi importante fonte de variação sobre a altura em todos os grupos, exceto para animais com 15 meses (grupo 4) e 18 meses (grupo 5). A mesma característica influenciou o peso nos grupos 5 (18 meses), 6 (21 meses) e 10 (acima de 48 meses) (Tabela 2).

O sexo influenciou significativamente a altura nos grupos 6 e 10, mas não afetou significativamente a característica peso. Alguns pesquisadores (Jones, 1987; Yamamoto et al., 1993; Heusner, 1992; Thompson et al., 1994; Pagan et al., 1996) afirmam que a taxa de crescimento nos machos é geralmente maior que nas fêmeas. Como os machos desta população, exceto garanhões, são castrados aproximadamente aos 24 meses de vida, esperava-se que o efeito de sexo não influenciasse o desenvolvimento dos animais após os dois anos de idade, pois, segundo Heusner (1997), a castração não influencia o desenvolvimento dos animais.

O efeito de raça foi significativamente importante para a altura dos animais somente nos grupos 5 (18 meses), 6 (21 meses) e 10 (mais de 48 meses) (Tabela 2). Nestes grupos, os animais PSI e BH foram mais altos ao sobreano que os demais. No grupo 10, isso não ocorreu e a raça Hanoveriana foi a mais alta. Contudo, para a característica peso, este efeito teve maior influência ao longo das faixas etárias, à exceção dos animais com menos de um e aos dois anos de idade. A raça Hanoveriana foi a mais pesada na
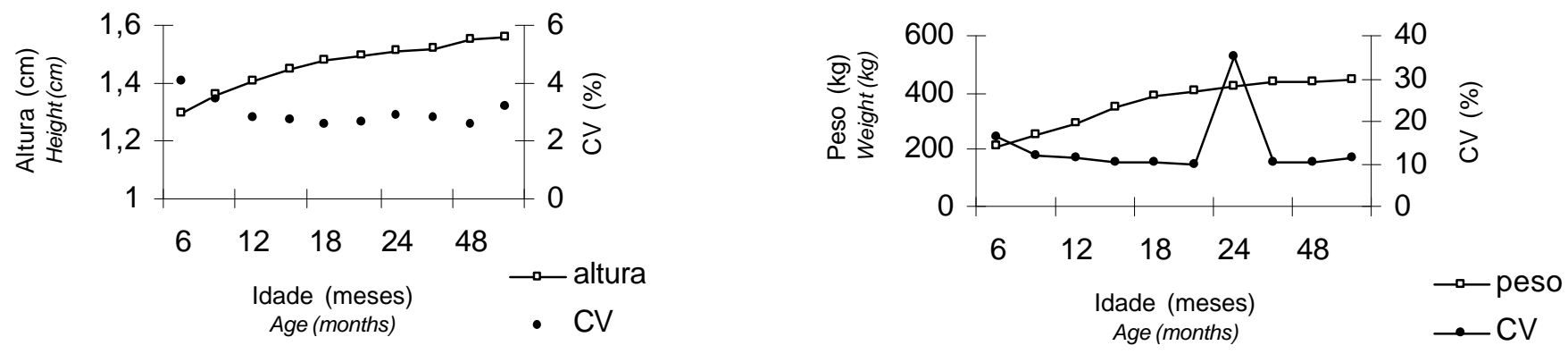

Figura 1 - Altura $(\mathrm{cm})$ e peso $(\mathrm{kg})$ e respectivos coeficientes de variação.

Figure 1 - Trends for height $(\mathrm{cm})$ and weight $(\mathrm{kg})$ according to age and respective coefficients of variation. 
Tabela 2 - Resumo da análise da variância para as características peso e altura dos cavalos do Exercito Brasileiro, de acordo com as classes de idade (grupo em meses)

Table 2 - Summary of analyses of variance for weight ant height of equines of the Brazilian army according to different ages (groups in months)

\begin{tabular}{|c|c|c|c|c|c|c|c|c|c|c|}
\hline \multicolumn{11}{|c|}{$\begin{array}{l}\text { Altura } \\
\text { Height }\end{array}$} \\
\hline Grupo & 1 & 2 & 3 & 4 & 5 & 6 & 7 & 8 & 9 & 10 \\
\hline \multicolumn{11}{|l|}{ Group } \\
\hline Idade (m) & 6 & 9 & 12 & 15 & 18 & 21 & 24 & 36 & 48 & +48 \\
\hline \multicolumn{11}{|l|}{ Age } \\
\hline mesn & $\mathrm{ns}$ & $\mathrm{ns}$ & $\mathrm{ns}$ & $\mathrm{ns}$ & $\mathrm{ns}$ & $\mathrm{ns}$ & $\mathrm{ns}$ & $* *$ & $\mathrm{~ns}$ & $* *$ \\
\hline anon & - & - & $*$ & $\mathrm{~ns}$ & $\mathrm{~ns}$ & $* *$ & $*$ & $*$ & $* *$ & $* * *$ \\
\hline sexo & $\mathrm{ns}$ & $\mathrm{ns}$ & $\mathrm{ns}$ & $\mathrm{ns}$ & $\mathrm{ns}$ & $* *$ & $\mathrm{~ns}$ & $\mathrm{~ns}$ & $\mathrm{~ns}$ & $* *$ \\
\hline raça & $\mathrm{ns}$ & $\mathrm{ns}$ & $*$ & $\mathrm{~ns}$ & $*$ & $*$ & $\mathrm{~ns}$ & $\mathrm{~ns}$ & $\mathrm{~ns}$ & $* * *$ \\
\hline mesm & - & $\mathrm{ns}$ & $\mathrm{ns}$ & $\mathrm{ns}$ & $\mathrm{ns}$ & $\mathrm{ns}$ & $\mathrm{ns}$ & $\mathrm{ns}$ & $\mathrm{ns}$ & $*$ \\
\hline anom & - & - & $*$ & $\mathrm{~ns}$ & $* *$ & $\mathrm{~ns}$ & $\mathrm{~ns}$ & $\mathrm{~ns}$ & $\mathrm{~ns}$ & $\mathrm{~ns}$ \\
\hline \multicolumn{11}{|c|}{$\begin{array}{c}\text { Peso } \\
\text { Weight }\end{array}$} \\
\hline mesn & $\mathrm{ns}$ & $\mathrm{ns}$ & $\mathrm{ns}$ & $\mathrm{ns}$ & $\mathrm{ns}$ & $\mathrm{ns}$ & $\mathrm{ns}$ & $*$ & $\mathrm{~ns}$ & $* *$ \\
\hline anon & - & - & $\mathrm{ns}$ & $\mathrm{ns}$ & $* *$ & $*$ & $\mathrm{~ns}$ & $\mathrm{~ns}$ & $\mathrm{~ns}$ & $* * *$ \\
\hline sexo & $\mathrm{ns}$ & $\mathrm{ns}$ & $\mathrm{ns}$ & $\mathrm{ns}$ & $\mathrm{ns}$ & $\mathrm{ns}$ & $\mathrm{ns}$ & $\mathrm{ns}$ & $\mathrm{ns}$ & $\mathrm{ns}$ \\
\hline raça & $\mathrm{ns}$ & $\mathrm{ns}$ & $\mathrm{ns}$ & $* *$ & $* * *$ & $* *$ & $\mathrm{~ns}$ & $* * *$ & $* *$ & $* * *$ \\
\hline mesm & - & $\mathrm{ns}$ & $\mathrm{ns}$ & $\mathrm{ns}$ & $\mathrm{ns}$ & $* * *$ & $\mathrm{~ns}$ & $* * *$ & $\mathrm{~ns}$ & $* * *$ \\
\hline anom & - & - & $\mathrm{ns}$ & $\mathrm{ns}$ & $\mathrm{ns}$ & $\mathrm{ns}$ & $\mathrm{ns}$ & $\mathrm{ns}$ & $\mathrm{ns}$ & $\mathrm{ns}$ \\
\hline
\end{tabular}

Mesn - mês de nascimento (month of birth), anon - ano de nascimento(year of birth), pel-pelagem (coat color), mesm - mês de mensuração (month of measurement), anom - ano de mensuração (year of measurement). ${ }^{*}(P<0,05) ;{ }^{* *}(P<0,01) ;{ }^{* * *}(P<0,001)$.

maioria dos grupos, exceto nos grupos 5 (18 meses) e 8 (36 meses), nos quais a raça $\mathrm{BH}$ apresentou maiores pesos. Os resultados encontrados eram esperados, pois, além do maior porte, a raça Hanoveriana também faz parte da composição genética da raça Brasileiro de Hipismo (Dias et al., 2000), o que é bem freqüente no rebanho de eqüinos do Exército pela utilização de garanhões desta raça.

O grupo 10, que compreende os animais com idade superior a 48 meses, foi o mais influenciado pelos efeitos fixos, comprovando que, mesmo que não sejam percebidos no decorrer do desenvolvimento do animal, determinados efeitos têm importância na fase adulta dos animais (Tabela 1).

Na Figura 2 são apresentados o peso (kg) e a altura (m) dos animais das raças Brasileiro de Hipismo e SRD.

A mesma tendência de crescimento foi observada para peso e altura em ambas as raças. A raça Brasileiro de Hipismo apresentou menor peso aos seis meses de idade em relação à SRD, mas aproximadamente a partir dos 18 meses de idade os animais BH passaram a ter maior peso (Figura 2). Quanto à altura, no início do crescimento, a diferença entre as duas raças estudadas foi mínima, apesar de que, a partir dos 12 meses de idade, os animais $\mathrm{BH}$ mostraram-se ligeiramente mais altos que os SRD.

Nas Tabelas 3 e 4 estão os resumos das análises de variância para as características peso e altura em cada um dos grupos para as raças Brasileiro de Hipismo e SRD, respectivamente.

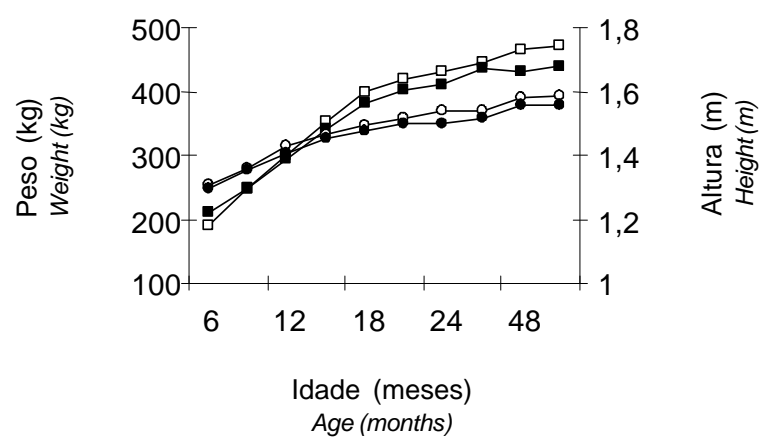

Figura 2 - Peso e altura dos animais das raças Brasileiro de Hipismo - (BH: n; O) e Sem Raça Definida (SRD: •; •), respectivamente.

Figure 2 - Weight and height of animals of $B H(\mathrm{n} ; 0)$ and $S R D(\cdot ; \bullet)$ breeds.

O efeito de idade da mãe (Tabela 3) só foi significativo sobre o peso dos animais quando em idade superior a 48 meses (grupo 10), o que não era esperado. Animais filhos de éguas com 5 a 12 anos de idade foram, em média, mais leves e ligeiramente mais baixos que os filhos de éguas mais velhas, com 13 a 19 anos de idade. Neste grupo, os filhos de éguas jovens (abaixo de cinco anos) não seguiram esta tendência e, portanto, não foram mais baixos e mais leves que os de éguas mais velhas.

Para a característica altura, o efeito da idade da mãe foi significativo para os grupos 8 (acima de 24 e até 36 meses) e 10 (acima de 48 meses de idade). Na característica altura, nota-se no grupo 8 influência significativa da idade da mãe sobre a altura, pois animais filhos de éguas de 5 a 12 anos 
Tabela 3 - Resumo da análise da variância das características peso e altura em dez classes de idade (grupos) para animais da raça Brasileiro de Hipismo

Table 3 - Summary of analyses of variance for weight and height of equines of the Brazilian Show jumper breed according to different ages (groups in months)

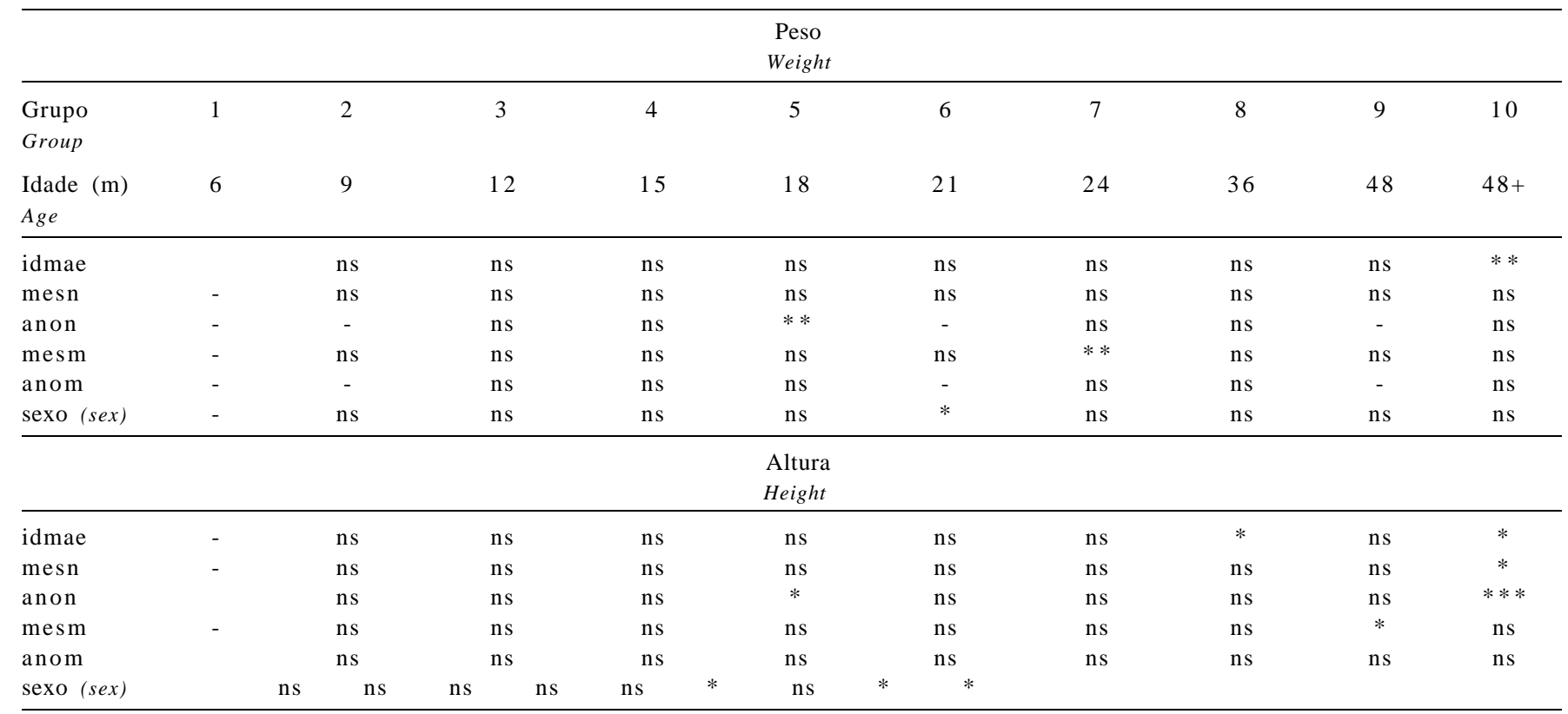

Mesn - mês de nascimento (month of birth), anon - ano de nascimento(year of birth), pel - pelagem (coat color), mesm - mês de mensuração (month of measurement), anom - ano de mensuração (year of measurement).

${ }^{*}(\mathrm{P}<0,05) ;{ }^{* *}(\mathrm{P}<0,01) ;{ }^{* * *}(\mathrm{P}<0,001)$.

Tabela 4 - Resumo da análise da variância das características peso e altura em dez classes de idade (grupos) para animais sem raça definida (SRD)

Table 4 - Summary of analyses of variance for weight ant height of equines of No Defined Breed according to different ages (groups in months)

\begin{tabular}{|c|c|c|c|c|c|c|c|c|c|c|}
\hline \multicolumn{11}{|c|}{$\begin{array}{c}\text { Peso } \\
\text { Weight }\end{array}$} \\
\hline Grupo & 1 & 2 & 3 & 4 & 5 & 6 & 7 & 8 & 9 & 10 \\
\hline \multicolumn{11}{|l|}{ Group } \\
\hline Idade (m) & 6 & 9 & 12 & 15 & 18 & 21 & 24 & 36 & 48 & $48+$ \\
\hline \multicolumn{11}{|l|}{ Age } \\
\hline idmae & $*$ & $\mathrm{~ns}$ & $\mathrm{~ns}$ & ns & $\mathrm{ns}$ & $\mathrm{ns}$ & ns & $\mathrm{ns}$ & $\mathrm{ns}$ & $* *$ \\
\hline mesn & - & $* * *$ & $\mathrm{~ns}$ & $*$ & $* * *$ & $* *$ & $* * *$ & $\mathrm{~ns}$ & ns & $\mathrm{ns}$ \\
\hline anon & - & - & $\mathrm{ns}$ & $\mathrm{ns}$ & $*$ & $* *$ & $\mathrm{~ns}$ & $\mathrm{~ns}$ & $*$ & $*$ \\
\hline mesm & - & $\mathrm{ns}$ & $\mathrm{ns}$ & $*$ & $* *$ & $* * *$ & $* * *$ & $*$ & $\mathrm{~ns}$ & $* * *$ \\
\hline anom & - & - & $\mathrm{ns}$ & $\mathrm{ns}$ & $\mathrm{ns}$ & $\mathrm{ns}$ & $\mathrm{ns}$ & $\mathrm{ns}$ & $* * *$ & $* * *$ \\
\hline sexo $(\operatorname{sex})$ & $*$ & $\mathrm{~ns}$ & $\mathrm{~ns}$ & $\mathrm{~ns}$ & $\mathrm{~ns}$ & $\mathrm{~ns}$ & $\mathrm{~ns}$ & $\mathrm{~ns}$ & $\mathrm{~ns}$ & $\mathrm{~ns}$ \\
\hline pai (sire) & $*$ & $*$ & $\mathrm{~ns}$ & $\mathrm{~ns}$ & $\mathrm{~ns}$ & $\mathrm{~ns}$ & $*$ & $\mathrm{~ns}$ & $\mathrm{~ns}$ & $\mathrm{~ns}$ \\
\hline \multicolumn{11}{|c|}{$\begin{array}{l}\text { Altura } \\
\text { Height }\end{array}$} \\
\hline idmae & $\mathrm{ns}$ & $\mathrm{ns}$ & $\mathrm{ns}$ & ns & $\mathrm{ns}$ & $\mathrm{ns}$ & $*$ & $\mathrm{~ns}$ & $\mathrm{~ns}$ & $* *$ \\
\hline mesn & - & $*$ & $\mathrm{~ns}$ & $* * *$ & $* * *$ & $* *$ & $* * *$ & $*$ & $\mathrm{~ns}$ & $\mathrm{~ns}$ \\
\hline anon & - & - & $\mathrm{ns}$ & $\mathrm{ns}$ & $\mathrm{ns}$ & $* *$ & $*$ & $\mathrm{~ns}$ & $\mathrm{~ns}$ & $* *$ \\
\hline mesm & - & $\mathrm{ns}$ & $*$ & $*$ & $* * *$ & $* * *$ & $* *$ & $\mathrm{~ns}$ & $*$ & $\mathrm{~ns}$ \\
\hline anom & - & - & $\mathrm{ns}$ & $*$ & $* * *$ & $*$ & $\mathrm{~ns}$ & $\mathrm{~ns}$ & $\mathrm{~ns}$ & $\mathrm{~ns}$ \\
\hline sexo $(\operatorname{sex})$ & $\mathrm{ns}$ & $\mathrm{ns}$ & $\mathrm{ns}$ & $\mathrm{ns}$ & $\mathrm{ns}$ & $\mathrm{ns}$ & $\mathrm{ns}$ & $\mathrm{ns}$ & $\mathrm{ns}$ & $*$ \\
\hline pai (sire) & $\mathrm{ns}$ & $* * *$ & $*$ & $*$ & $* *$ & $* * *$ & $* * *$ & $* *$ & $\mathrm{~ns}$ & $\mathrm{~ns}$ \\
\hline
\end{tabular}

Mesn - mês de nascimento (month of birth), anon - ano de nascimento(year of birth), pel - pelagem (coat color), mesm - mês de mensuração (month of measurement), anom - ano de mensuração (year of measurement).

${ }^{\star}(P<0,05) ;{ }^{* *}(P<0,01) ;{ }^{* * *}(P<0,001)$. 
de idade tiveram altura menor $(1,53 \mathrm{~m})$ que a dos filhos de éguas com 15 a 19 anos de idade (média de 1,56 m). Esse resultado difere do relatado por Silveira (2001), que observou que fêmeas mais velhas tiveram filhos menores.

O efeito de mês de nascimento não influenciou significativamente o peso dos animais nos diversos grupos etários, assim como a característica altura, exceto no grupo $10(\mathrm{P}<0,05)$. Neste grupo, os animais nascidos no final do inverno (agosto e setembro) foram, em média, mais altos que os nascidos na primavera e no verão, ainda que com média de idade (em dias) menor que nesses dois últimos períodos de nascimento. Estes resultados são semelhantes aos descritos por Thompson et al. (1994) para animais PuroSangue Inglês.

$\mathrm{O}$ efeito de ano de nascimento influenciou as características peso e altura no grupo 5 (animais de 15 a 18 meses), observando-se que os animais nascidos em 1996 foram os mais altos e pesados. Este fato coincide com a criação do órgão de acompanhamento e controle com políticas voltadas para a atividade, com maior incremento de incentivos e aporte de verbas. Os animais nascidos em 1996 mantiveram-se entre os mais altos no grupo $10(\mathrm{P}<0,001)$, juntamente com os nascidos nos anos subseqüentes, o que comprova que os investimentos na melhoria das condições ambientais (preparo de pastagens de inverno, aporte constante de concentrado de boa qualidade, suplementação mineral eficiente e realização criteriosa de medidas profiláticas) promoveram melhores resultados.

Verificou-se influência significativa do mês de mensuração sobre a característica peso no grupo 7 (acima de 21 até 24 meses), correspondendo ao final do sobreano. Animais medidos ao final do inverno e início da primavera apresentaram média de peso maior que a daqueles pesados nas outras estações do ano (verão e outono). Na região em que este trabalho foi realizado, existe a possibilidade do cultivo de forrageiras de ciclo hiberno-primaveril, como aveia, azevém e trevo, que possuem excelentes índices nutricionais, o que melhoraria as condições dos animais ao final do inverno (Alfaya et al., 2001b; Rocha et al., 2001). O mês de mensuração influenciou a altura dos animais no grupo 9 (maior que 36 até 48 meses), promovendo a mesma diferença anteriormente relatada, com animais apresentando maiores alturas no decorrer da estação de forrageiras de clima temperado.

O sexo não foi significativamente importante nas faixas etárias até o sobreano, tanto para peso quanto para a altura, exceto para o peso no grupo 6 e para altura no grupo 7 $(\mathrm{P}<0,05)$. Na faixa etária do grupo 6 , os machos foram mais pesados que as fêmeas, entretanto, no grupo 7 , as fêmeas revelaram-se ligeiramente mais altas. Yamamoto et al. (1993) afirmaram que, em geral, machos apresentam valores maiores para peso e altura, fato relatado também por Thompson et al. (1994). O fator sexo só voltou a influenciar a característica altura nos grupos $9(\mathrm{P}<0,05)$ e $10(\mathrm{P}<0,05)$, quando os machos foram maiores que as fêmeas. A ocorrência de fases em que as fêmeas apresentam melhor desenvolvimento em relação aos machos difere também do observado por Pagan et al. (1996), que, ao estudarem potros PSI até os 18 meses, notaram que os machos foram mais pesados e mais altos durante todo o período estudado.

De acordo com dados publicados por Souza et al. (1997) para a raça Brasileiro de Hipismo aos 12 meses, cavalos apresentaram altura média de $1,35 \mathrm{~m}$ e peso médio de $286 \mathrm{~kg}$. Os potros da Coudelaria de Rincão apresentaram, de modo geral, melhor desenvolvimento aos 12 meses, com altura média de 1,43 m e peso médio de $301,2 \mathrm{~kg}$. Aos 18 meses, os animais do Exército permaneceram mais altos $(1,49 \times 1,45 \mathrm{~m})$, porém ligeiramente mais leves $(398,2 \times 400 \mathrm{~kg})$. A diferença de altura continuou aos 24 meses $(1,541,48 \mathrm{~m})$. Houve ainda recuperação em relação ao peso $(431,2$ x $421 \mathrm{~kg})$.

$\mathrm{Na}$ Tabela 4 constam os resultados da análise da variância das características peso e altura nos diversos grupos etários, de acordo com diversos efeitos fixos em animais SRD. O efeito da idade da mãe influenciou o peso dos animais até os seis meses de idade, entretanto, a média de peso dos animais filhos de éguas com 5 a 12 anos de idade foi menor nesta faixa etária que em idade mais avançadas. Também a média de altura no grupo 7 (acima de 21 até 24 meses) foi menor para filhos de éguas mais novas, fato que não se confirmou na maturidade, quando, no grupo 10 ( $\mathrm{P}<0,01)$, os filhos de éguas com 5 a 12 anos de idade foram, em média, mais pesados que os filhos de éguas mais velhas, embora a média das alturas de ambos tenha sido idêntica $(1,57 \mathrm{~m})$. Interessante destacar que filhos de éguas com idade inferior a 5 anos foram menores e mais leves que os de éguas em idade mais adequada de reprodução. Na literatura, há relatos de que filhos de éguas de primeiro parto nascem com menor peso (Kulisa et al., 1995).

$\mathrm{O}$ mês de nascimento teve maior influência sobre as características peso e altura, especialmente ao sobreano, entre 12 e 24 meses de idade (Tabela 4). Durante esse período, os potros nascidos no inverno foram, em geral, mais altos e pesados que os nascidos na primavera, que, por sua vez, superaram os animais nascidos no verão. Essa tendência se manteve na maturidade (grupo 10), com exceção dos potros nascidos no verão, que passaram a ser mais pesados que os produtos da primavera, embora com menor estatura. Para potros PSI, Pagan et al. (1996) relataram que 
a taxa de crescimento ao sobreano foi mais uma função da estação do ano do que da idade, divergindo do que foi encontrado ao sobreano nos animais em estudo, cujo crescimento foi fortemente influenciado pelo mês de nascimento.

$O$ efeito de ano de nascimento influenciou significativamente as características peso e altura dos animais ao sobreano, com idade entre 18 e 24 meses, porém, somente para a característica peso este fator teve efeito nas fases finais de crescimento e maturidade (Tabela 4). Hintz (1992) afirmou que o ganho de peso corporal pode ser mais fortemente afetado pela privação de energia ou proteína que a altura, ou seja, os cavalos podem crescer, embora em ritmo mais lento, ainda que não ganhem peso. Como o animal SRD apresenta maior vigor, a altura final pode não ter sido influenciada pelo ano de nascimento e, conseqüentemente, pelo ambiente proporcionado, seguindo a tendência ao sobreano.

Nos animais SRD medidos ao sobreano, houve influência significativa do mês de mensuração sobre peso e altura e somente para a característica peso, esta influência ocorreu também na maturidade (Tabela 4). Este grupo genético não seguiu o mesmo padrão da raça $\mathrm{BH}$ ou do restante do rebanho. Quando houve influência do mês de mensuração, os animais foram mais pesados no outono, no início do sobreano, observando-se que a influência sobre a altura variou nessa fase. Os grupos 6 e 7 (correspondentes ao final do sobreano) foram os que voltaram a assumir o padrão verificado no rebanho e na raça $\mathrm{BH}$, com o final do inverno e início da primavera se caracterizando como época em que os animais em desenvolvimento foram maiores. À maturidade, quando o mês de mensuração volta a influenciar o peso, verifica-se novamente a participação da pastagem de ciclo hiberno-primaveril como agente promotor do ganho de peso, por sua qualidade nutricional e, sobretudo, pela administração simultânea de concentrados, especialmente para os animais das regiões Sul e Centro-Oeste. Além disso, os animais SRD apresentaram menor desenvolvimento corporal em todos os grupos, caracterizando-se por não apresentar alta taxa de crescimento, o que revelaria menor nível de exigência nutricional dos potros. As exigências de energia do potro desmamado dependem da idade, da taxa de crescimento e do potencial de crescimento utilizado (Saastamoinen, 1996). Assim, menores taxas de crescimento podem ter reduzido as exigências nutricionais dos potros, permitindo crescimento em diferentes épocas do ano.

Entre os animais SRD, o sexo não influenciou o peso em nenhum dos grupos etários (Tabela 4). Resultado semelhante ocorreu para a altura, com exceção do grupo 10
$(\mathrm{P}<0,05)$, pois, à maturidade os machos foram maiores que as fêmeas (Tabela 4). Ressalta-se que, embora os machos sejam castrados aos 24 meses, é possível que ocorram diferenças entre os sexos. Heusner (1997) estudou potros castrados entre 2 dias e 2 meses de idade e não encontrou diferenças nas taxas de crescimento entre potros castrados e não-castrados até 12 meses de idade.

Foram estimados os coeficientes de herdabilidade para as medidas de desenvolvimento corporal das raças Brasileiro de Hipismo e SRD. Os animais foram divididos em quatro grupos de acordo com sua faixa etária (Tabela 5). Para os animais $\mathrm{BH}$, as herdabilidades para o peso foram altas nos diversos grupos, mas as estimativas obtidas para a característica altura foram baixas em todos os grupos. O comportamento de ambas as características foi idêntico tanto para os animais BH como para os SRD. De modo geral, nos dois grupos genéticos, a estimativa de herdabilidade para peso aumentou de acordo com as faixas etárias (Tabela 5), o que está de acordo com dados encontrados por Lawrence et al. (2002), que sugeriram que pesos em idades jovens tendem a ter menor herdabilidade que em idades mais tardias. No mesmo trabalho, os autores afirmam que as taxas de crescimento geralmente possuem herdabilidade de média a alta e que é preciso considerar os fatores que controlam a taxa de progresso, o que depende do diferencial de seleção e do intervalo de gerações, pois o diferencial de seleção mede a superioridade dos pais selecionados sobre a média da população de origem. Assim, para obter alto diferencial de seleção, é necessário ter grande número de animais com grande variabilidade.

Entretanto, a herdabilidade para a altura nos diversos grupos foi baixa (Tabela 5). Como nos cavalos desta população existe tendência de seleção constante para altura, provavelmente a reduzida variabilidade genética contribuiu para esses resultados. Os valores encontrados foram inferiores aos relatados por Zamborlini (1996) e Costa

Tabela 5 - Estimativas de herdabilidade aditiva direta das características de desenvolvimento corporal (peso e altura) em cavalos do Exército Brasileiro

Table 5 - Heritability estimates for growth traits (weight and height) of equines of the Brazilian army

\begin{tabular}{lccccc}
\hline $\begin{array}{l}\text { Raça* } \\
\text { Breed }\end{array}$ & $\begin{array}{c}\text { Idade } \\
\text { Age }\end{array}$ & $\begin{array}{c}\text { 1 ano } \\
\text { 1 year }\end{array}$ & $\begin{array}{c}2 \text { anos } \\
2 \text { years }\end{array}$ & $\begin{array}{c}3 \text { anos } \\
\text { 3 years }\end{array}$ & $\begin{array}{c}4 \text { anos } \\
4 \text { years }\end{array}$ \\
\hline BH & Peso (Weight) & 0,54 & 0,50 & 0,68 & 0,68 \\
& Altura (Height) & 0,04 & 0,12 & 0,00 & 0,00 \\
\multirow{2}{*}{ SRD } & Peso (Weight) & 0,38 & 0,60 & 0,52 & 0,56 \\
& Altura (Height) & 0,01 & 0,08 & 0,08 & 0,02
\end{tabular}

*BH: Brasileiro de Hipismo (Brazilian Show jumper); SRD: sem raça definida (No defined breed). 
(1998), que encontraram valores de 0,52 e 0,65 para Pônei Brasileiro e Mangalarga Marchador, respectivamente.

Na Tabela 6 são apresentadas as correlações genéticas estimadas entre as características peso e altura para os animais das raças Brasileiro de Hipismo (BH) e SRD. Para a raça $\mathrm{BH}$, observou-se correlação genética de maior magnitude entre peso e altura na fase inicial da vida, assim como nas fases finais de crescimento, e valores menores nas fases intermediárias. Nestas fases, houve maior participação do ambiente na relação entre as características fenotípicas dos indivíduos. Nos animais SRD, o comportamento não mudou significativamente ao longo do tempo. Nas fases intermediárias, a correlação genética não tendeu a diminuir e, portanto, a relação entre as características estudadas nos animais SRD foi menos influenciada pela variação ambiental. Os resultados obtidos neste trabalho são semelhantes aos relatados por Pereira (1996), que encontrou correlação genética positiva, com valores de média a elevada magnitude.

A correlação originada pela pleiotropia expressa a forma como duas características são influenciadas pelos mesmos genes, mas a correlação resultante desse fenômeno expressa o efeito final de todos os genes que estão segregando e que interferem em ambas as características (Falconer, 1987). Para as características estudadas, o efeito final da ação dos genes foi aumentar o desempenho em cada uma delas, indicando que a seleção para o aumento de uma acarreta melhoria na outra, promovendo o melhoramento em ambas, simultaneamente.

Tabela 6 - Correlações genéticas entre peso e altura em diferentes classes de idade para as raças Brasileiro de Hipismo e SRD

Table 6 - Genetic correlations between weight and height in equines of the Brazilian Show jumper (BH) and no defined breed (SRD), by age class

\begin{tabular}{lcc}
\hline $\begin{array}{l}\text { Raça } \\
\text { Breed } \\
\text { Grupo } \\
\text { Class }\end{array}$ & BH & SRD \\
\hline 1 & P - A & P - A \\
2 & 1,00 & $0,75 * * *$ \\
3 & $0,72 * * *$ & $0,76 * * *$ \\
4 & $0,49 * * *$ & $0,48 * * *$ \\
5 & $0,58 * * *$ & $0,71 * * *$ \\
6 & $0,60 * * *$ & $0,64 * * *$ \\
7 & $0,51 * * *$ & $0,56 * * *$ \\
8 & $0,49 * * *$ & $0,55 * * *$ \\
9 & $0,48 * * *$ & $0,54 * * *$ \\
10 & $0,70^{* * *}$ & $0,68 * * *$ \\
\hline
\end{tabular}

${ }^{*}(\mathrm{P}<0,05) ;{ }^{* \star}(\mathrm{P}<0,01) ;{ }^{* * *}(\mathrm{P}<0,001)$.

$\mathrm{P}=$ peso (weight); $\mathrm{A}=$ altura (height)

\section{Conclusões}

Os efeitos ambientais que não influenciam nas fases jovens podem ser importantes na idade adulta.

As estimativas de herdabilidade obtidas para peso variaram de moderada a alta, indicando que esta característica pode responder à seleção individual.

As correlações genéticas estimadas para peso e altura comprovaram que, nas raças Brasileiro de Hipismo e SRD, ao selecionar para peso poderão ser obtidos ganhos para a altura, na população estudada.

\section{Literatura Citada}

ALFAYA, H.; ALVES-BRANCO, F.P.J.; SAPPER, M.F.M. et al. Consumo de nutrientes por animais em crescimento em campo natural com ou sem suplementação alimentar na estação fria. In: REUNIÃO ANUAL DA SOCIEDADE BRASILEIRA DE ZOOTECNIA, 38., 2001, Piracicaba. Anais... Piracicaba: Sociedade Brasileira de Zootecnia, 2001a. p.357-358.

ALFAYA, H.; ALVES-BRANCO, F.P.J.; SAPPER, M.F.M. et al Energia e proteína disponíveis na vegetação de campo natural no período hibernal. In: REUNIÃO ANUAL DA SOCIEDADE BRASILEIRA DE ZOOTECNIA, 38., 2001, Piracicaba. Anais... Piracicaba: Sociedade Brasileira de Zootecnia, 2001b. p. 378-379.

BOLDMAN, K.G.; KRIESE, L.; Van VLECK, L.D. et al. A manual for use for MTDFREML: a set of programs to obtain estimates of variance and covariance [DRAFT]. Lincoln: Department of Agriculture/Agricultural Research Service, 1995. 120p

COSTA, M.D.; BERGMANN, J.A.G.; PEREIRA, C.S. et al. Avaliação dos fatores genéticos e de ambientes que interferem nas medidas lineares dos Pôneis da raça Brasileira. Revista Brasileira de Zootecnia, v.27, n.3, p.491-497, 1998.

DIAS, I.M.G.; BERGMANN, J.A.G.; REZENDE, A.S.C. et al. Formação e estrutura populacional do eqüino Brasileiro de Hipismo. Arquivo Brasileiro de Medicina Veterinária e Zootecnia, v.52, n.6, p.647-654, 2000.

FALCONER, D.S. Introdução à genética quantitativa. Trad. Martinho, A.S.; Silva, J.C. Viçosa, MG: Universidade Federal de Viçosa, 1987. 279p.

HEUSNER, G.L. Effect of month of birth on the size of foals Journal of Equine Veterinary Science, v.12, n.5, p.297300,1992

HEUSNER, G.L.; POPE, J.B.; CROWELL-DAVIS, S.L. et al. The effect of early prepubertal castration on the growth and behavior of colts. In: EQUINE NUTRITION AND PHYSIOLOGY SYMPOSIUM, 15., 1997, Fort Worth, Proceedings... Fort Worth: 1997, p.223-224.

HINTZ, H.F. Effect of energy and protein deprivation on bodyweight and height gains of young horses. Equine Practice v.14, n.1, p.7-8, 1992.

JONES, W.E. Genética e criação de cavalos. São Paulo: Roca, 1987. 666p.

KULISA, M.; LUSZCZYNSKI, J. Some factors affecting gestation period of purebred Arab mares at the Michalow stud. Zeszyty Naukowe Akademii Rolniczej im. Hugona Kollataja w Krakowie. Seria: Zootechnika, v.30, p.115-123, 1995.

LAWRENCE, T.L.J.; FOWLER, V.R. Growth of farm animals. Wallingford: Cabi International, 2002. 347p 
PAGAN, J.D.; JACKSON, S.G.; CADDEL, S. A summary of growth rates of thoroughbreds in Kentucky. Pferdeheilkunde, v.12, p.285-289, 1996.

PEREIRA, J.C.C. Melhoramento genético aplicado à produção animal. Belo Horizonte: Universidade Federal de Minas Gerais, 1996. 416p.

ROCHA, M.G.; RESTle, J.; PILAU, A. et al. Produção animal e retorno econômico da suplementação em pastagem de aveia e azevem. Ciência Rural, v.33, n.2, p.200-205, 2003.

SAASTAMOINEN, M.T. Protein, amino acid and energy requirements of weaning foals and yearlings - A review. Nutrition and nutritional related disorders in the foal. In: EUROPEAN CONFERENCE ON HORSE NUTRITION, 2., 1996, Celle. Proceedings... Celle: Pferdeheilkunde, 1996. v.12, n.3, p.297-302.

STATISTICAL ANALYSIS SYSTEM - SAS. User's guide. Cary: 1996. $595 \mathrm{p}$.

SgEX. [2003]. Boletim do Exército. Disponível em: <http:// www.sgex.eb.mil.br/boletim/BE003/PortDestaques/sepbepde. PDF> Acesso em: 24/05/2006.

SILVEIRA, J.C.; McMANUS, C.; MASCIOLI, A.S. et al. Fatores ambientais e parâmetros genéticos para características produtivas e reprodutivas em um rebanho Nelore no Estado do Mato Grosso do Sul. Revista Brasileira de Zootecnia, v.33, n.6, p.1432-1444, 2004.
SOUZA, J.A.T.; GACEK, F.; OLIVEIRA, J.V. et al. Desenvolvimento corporal e estabelecimento da puberdade em potras da raça Brasileira de Hipismo. Revista Brasileira de Reprodução Animal, v.21, n.3, p.117-120, 1997.

THOMPSON, K.N.; SMITH, B.P. Skeletal growth patterns of thoroughbred horses. Journal of Equine Veterinary Science, v.14, n.3, p.148-151, 1994.

YAMAMOTO, O.; ASAI, Y.; KUSUNOSE, R. Effects of sex, birth month, parity, weight of dam and farm on the growth of Thoroughbred foals and yearlings. Animal Science and Technology, v.64, n.5, p.491-498, 1993.

ZAMBORLINI, L.C.; PEREIRA, J.C.C. Melhoramento genético de eqüinos. In: PEREIRA, J.C.C. (Ed.) Melhoramento genético aplicado à produção animal. Belo Horizonte: Universidade Federal de Minas Gerais, 1996. 416p. 